\title{
UNDERSTANDING THE WEAKNESSES AND THE THREATS OF CONTINUOUS MEDICAL EDUCATION IN THE 21st CENTURY
}

\author{
Eleni D. Politi, Kyriakos N. Souliotis \\ University of Peloponnese, Corinthos, Greece \\ E-mail: releni@yahoo.com, soulioti@hol.gr
}

\begin{abstract}
The European Union of Medical Specialties is taking efforts to harmonize Continuous Medical Education (CME) requirements in Europe. However, in an era of financial crisis, some countries may undervalue the long-term public health impact of weak and budget-limited CME national systems. Appreciating the statement of the Greek ancient philosopher Socrates: "If you think that education is expensive, you should consider ignorance", an assessment of the Greek CME system and its possible areas of improvement is attempted. From a questionnaire-based survey conducted to one hundred Greek practicing physicians, it seems that the vast majority respects the values of CME. However, they do not seem to clearly perceive CME as an obligatory, neither as an outcomes controlled process. They also confess CME access difficulties and geographic and financial discriminations. Overall, the Greek CME system was characterized as a non-satisfactory one and it did not seem to meet the physicians'specific needs. Reviewing for relevant concerns also in a global context, it appears that institutionally mandating CME, controlling for the quality and the outcomes of it, as well as CME funding issues, they are all concepts where either robust evidence lacks and/or improvements warrant. Taking into consideration the above, a Greek CME system reformation is considered as utmost relevant and the comprehensive establishment of a National CME Authority, dedicated to address the above issues, is also suggested.

Key words: accreditation of medical education, continuous medical education, continuous professional development, public health institutions and policies.
\end{abstract}

\section{Introduction}

Even long in the past already, it was estimated that the half-life of knowledge acquired in Medicine was approximately five years (Lindsay, Morrison \& Kelley, 1974). The medical sciences knowledge base is considered to be a continuously expanding one (Institute of Medicine, 2001), therefore, it is even more essential nowadays that medical professionals follow continuous, life-long training programmes to keep aligned with developments in medicine and to constantly improve their practicing skills (Mc Partland, n.d.).

\section{The Efforts and the Difficulties to Meet the Fundamental Goals of Continuous Medical Education}

Continuous Medical Education (CME) and Continuous Professional Development (CPD) in medicine principally serve so as the quality and outcomes of delivered care are continuously improved (Fox \& Bennet, 1998).

In order to meet such goals, it is a required obligation in several countries that medics follow accreditated $\mathrm{CME} / \mathrm{CPD}$ programmes and they are periodically relicensed to practice. In other countries though, mandatory $\mathrm{CME} / \mathrm{CPD}$ is not clearly regulated (General Medical Council, 2011), (American Medical Association, 2010).

On the other hand, it is said that the motivation for life-long CME should not be led by an anxiety to meet accreditation requirements (Mc Partland, n.d.). The health care profession- 


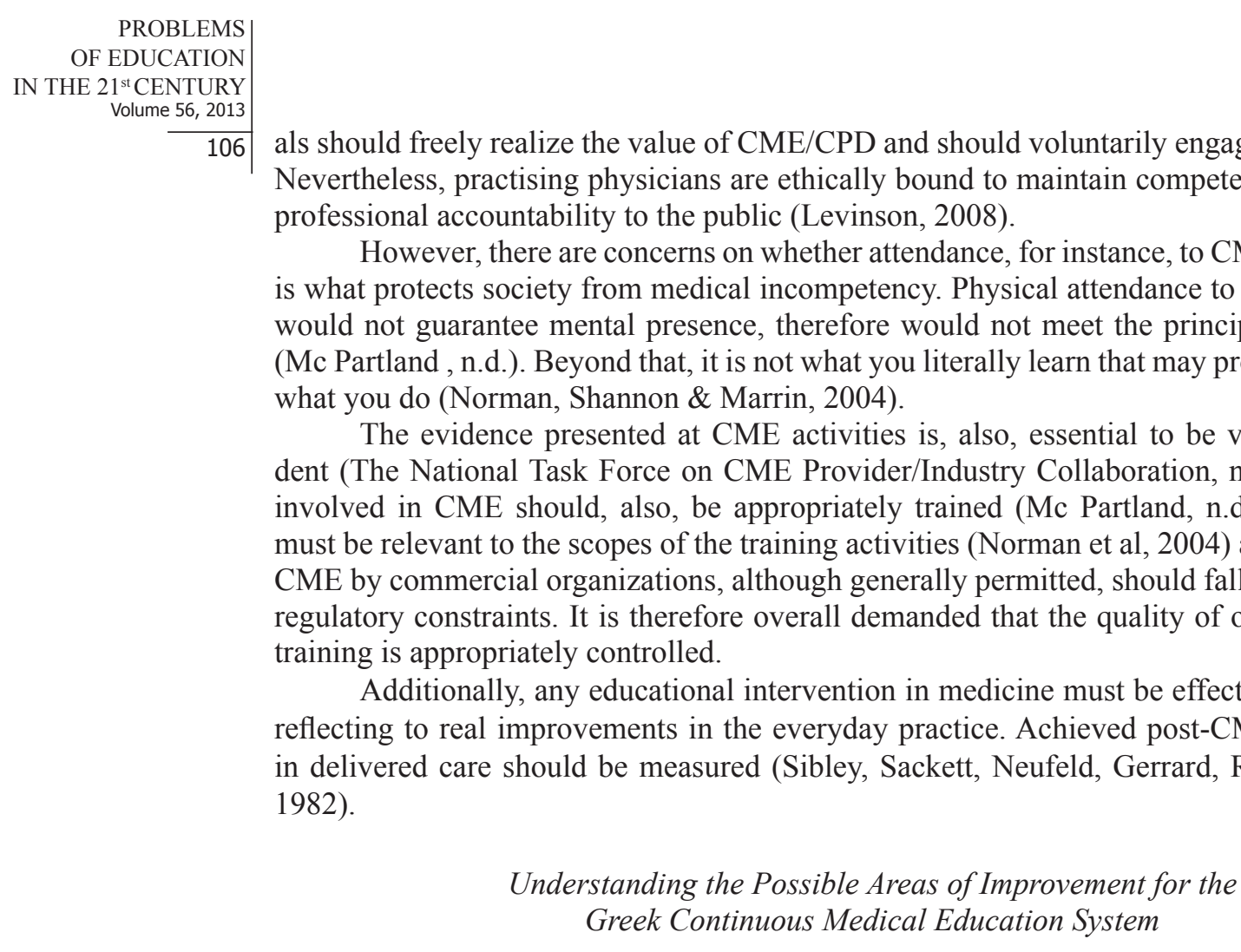

In Greece, after the completion of a medical degree and speciality, it is actually up to the individual to synchronize an update to ongoing developments in medicine. There is not any obligation for targeted, pre-specified continuous retrain, neither any systematic inspection of updated proficiency in medical knowledge and practice.

Greek physicians' obligation for general postgraduate training and for declaring on an every-five-years basis of the hours spent for CME has been described in past Official Greek Government Gazettes (NHS Formation, 1983). There have been also discussions on the establishment of periodic relicensing examinations. In Greece however, never came into force any measure for planning and inspecting on physicians' CME obligations, neither was developed any medical profession relicensing model.

Most CME activities taking place in Greece are governed by the EACCME (European Accreditation Council for CME) principles for accreditation. The two main national authorities responsible for inspecting their roll out and quality are the Greek National Drug Organization and the Hellenic Medical Association. Still though there is not any central control for avoiding duplication in delivered activities, for sources saving or for covering distant areas of the country, neither for monitoring how CME interventions satisfy targeted educational needs, if they reflect to real improvements in clinical practice or if they overall manage to meet intended goals.

Meeting the fundamental goals of CME, i.e. improving patients' care and outcomes, is of public health interest. For that reason, addressing possible weaknesses in the CME process, in particular through understanding the practicing physicians' feedback and requested needs, is of utmost value. On that scope, a research project has been initiated. It consists of a three axis approach and aims to explore possible need for improvements in the national CME/CPD system and to suggest ways of addressing the identified needs. On the one axis, an overview of the constitutional and political Greek CME/CPD framework and of the ways CME/CPD activities are organized and offered in the country is made. National CME/CPD systems of other countries and the drivers of recent reformations are also overviewed. On another axis, a survey that brings evident light to the attitudes and beliefs the Greek practicing physicians have against CME/ CPD is conducted. On a third axis, suggestions for improvements and for reformation of the 
Greek CME/CPD System are attempted. The outcomes of the survey are here presented and the

To the authors' best knowledge, this is a unique study conducted in Greece, aiming to capture the practicing doctors' beliefs, attitudes and proposals for CME/CPD, in an era of prescribing limitations and strict regulations in clinical practice and with the scope to use this evidence, alongside the shared experience of other countries, for proposing relevant improvements in the national CME/CPD system.

\section{Methodology of Research}

\section{General Background of Research}

The survey of this research project was conducted on September 2012 in Athens. The study population comprised specialized or resident doctors practicing medicine in an NHS Unit. The General Hospital of Athens "Georgios Gennimatas" (GNA) was identified as a suitable sampling unit to conduct this survey, as GNA Hospital is one of the biggest and busiest Tertiary Care Centers in Greece. It ranks $1^{\text {st }}$ among the General hospitals of Attica for "Numbers of hospitalized patients" and $2^{\text {nd }}$ among the Tertiary hospitals of Greece for "Numbers of outpatient visits" (Greek Ministry of Health \& Welfare, February 2012). It is a referral NHS hospital, with access to most laboratory, surgical and internal medicine specialities. It is also a resident doctors' training center.

\section{Sample of Research}

The sample of research was composed of one hundred (100) physicians from all sector units of the GNA hospital. Thirty eight percent of them were Internal medicine sector physicians, 33\% were Laboratory sector physicians and 29\% were Surgical sector physicians. Female doctors' share in the sample was $36 \%$. Fifty percent of physicians were aged below 35 years old (38,5\% were between 35 to 45 years old). The mean age of women was 40 years (SD 9.3 years) whereas the mean age of male doctor equaled 36 years (SD 4.9 years). Overall mean age equaled 37 years (SD 7.0 years). The majority of the corresponding sample (64\%) had studied Medicine in Greece, whereas 27\% in Eastern Europe countries and the rest elsewhere in Europe. The analogies of this random sample did not seem to substantially deviate the expected analogies of the total number of doctors working in GNA Hospital and since its selection was random, it was considered to be a representative sample. However, specific tests were not done.

\section{Instrument and Procedures}

The survey tool of the research was a questionnaire of twelve closed multiple choice questions, including also a free narrative space on last page, in order to provide the interrogated persons with the opportunity to freely express potential additional thoughts. Extra fields for the collection of demographic data were provided. The questionnaire was informative on the scope of the survey and the time asked for its completion was freely provided. With this questionnaire it was aimed to collect information on general beliefs, attitudes, preferences, criticism and proposals on $\mathrm{CME} / \mathrm{CPD}$, in order to identify the developing trends and consequently the challenges pertaining to the needed advancement of the current CME/CPD system in Greece. To identify what exact questions would be useful to include in this survey, a general bibliographic overview of the concepts being discussed for CME/CPD had preceded the questionnaire development. The physicians of the sampling unit were randomly approached and asked to be voluntarily and anonymously included in the research sample. 
Eleni D. POLITI, Kyriakos N. SOULIOTIS. Understanding the Weaknesses and the Threats of Continuous Medical Education in the 21st Century

PROBLEMS

OF EDUCATION

IN THE $21^{\text {st }}$ CENTURY

Volume 56,2013

108

\section{Data Analysis}

Out of the one hundred questionnaires (100) that were handed out to the sampling units, ninety eight completed questionnaires were collected. The collected data were inserted in a dataset and a codebook was developed. Statistical analysis of the primary data was conducted using IBM SPSS Statistics 20 package. The level of statistical significance was set at $5 \%$. Hypothesis testing was performed using parametric statistical techniques (one-way analysis of variance) and non-parametric techniques (Kruskal-Wallis one way analysis of variance by ranks), as well.

\section{Results of Research}

\section{Beliefs and Attitudes on Continuous Medical Education}

The vast majority of this sample (95\%) considered CME as a determining or at least an important parameter for Good Clinical Practice (GCP) and for Patients' safety protection (Figure 1) and ranked its importance highly in a scale from 1 to 10 (Figure 2). It should be noted that the mean rating of the importance of CME is remarkably high (mean 8.9; SD 1.26) and does not differ significantly by age group (p-value $12.4 \%$ ), sex (p-value $75.0 \%$ ), work status (p-value $14.4 \%$ ), medicine sector (p-value $56.4 \%$ ) or doctors' speciality (p-value $86.0 \%$ ).

\section{CME as a parameter for GCP and for patient safety protection}

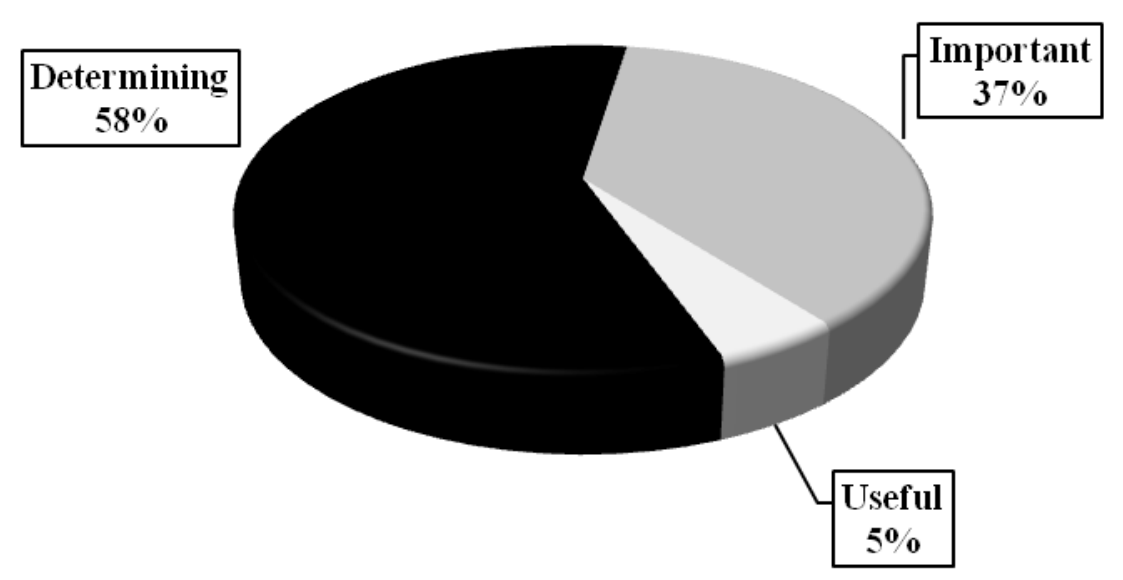

Figure 1: The corresponding doctors' opinion on the connection of CME with GCP and patient's safety protection. 


\section{Ranking CMIE importance in a scale from 1 to 10 ( $1=0$ f secondary importance, $10=$ important $)$}

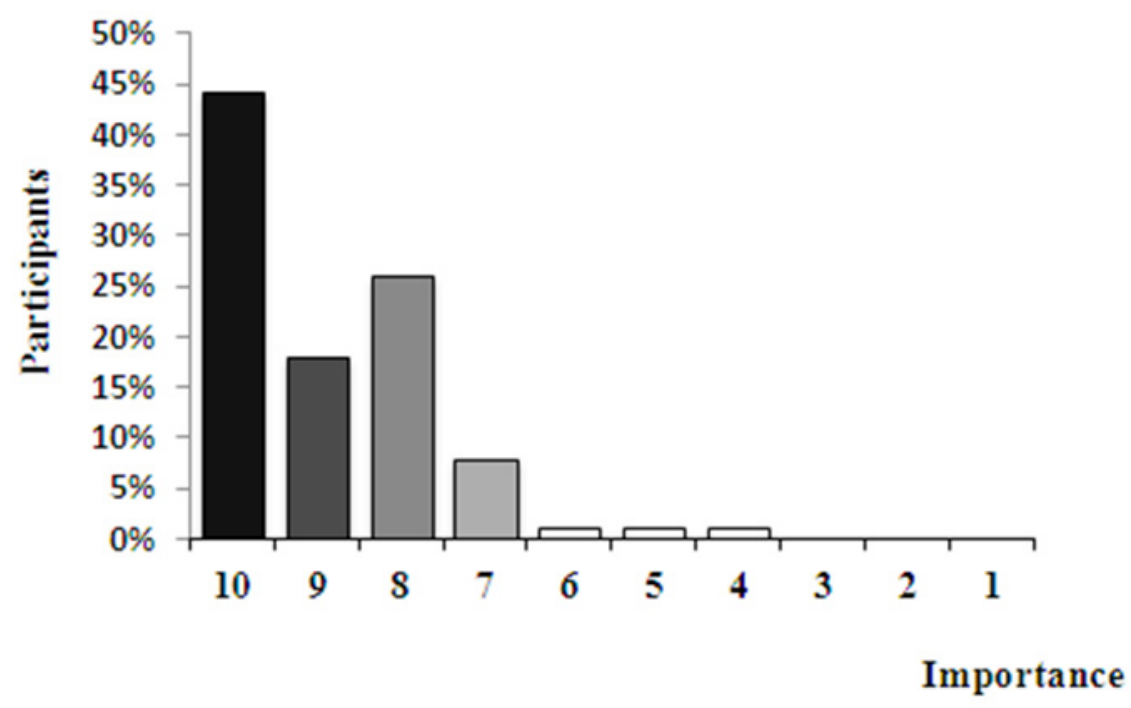

Figure 2: The corresponding doctors' opinion on CME's importance on a 1-10 scale.

Although the majority of the corresponding sample (95\%) seemed to consider CME highly important, it was not equally high the percentage of them $(73 \%)$ that confessed a frequent pursue. It is noteworthy that the Surgical sector appeared to pursue CME more strongly compared to the others ( $86 \%$ pursue CME frequently), with the Laboratory medicine sector coming second (78\% pursue CME frequently) and the Internal sector coming third (56\% pursue CME frequently) and these differences were significant ( $p$-value $1.9 \%)$. Moreover, none $(0 \%)$ of the questioned physicians was knowledgeable of whether they have obligations for annual CME credits collection and how the accreditation system works. There seems to be a gap between the strong theoretical perception of CME as important and the eventual practical pursue of it, raising questions for why this controversy appears.

Maybe this is explained by the fact that offered CME activities do not meet the practicing physicians' real needs or because access difficulties prevent their intentions or because CME is not obligatory. Indeed, only $6 \%$ of the corresponding sample considers that the current national Greek CME system is satisfactory. The observed lack of satisfaction against the Greek CME system was independent of medical speciality, age or gender.

\section{Criticism and Preferences for CME Practices}

The vast majority of the sample (95\%) did not agree that the accreditation system translates to real competency values (Figure 3). Moreover, the majority (68\%) of the physicians was not sure if the attendance to congresses satisfies real CME needs, although it represents the dominant kind of pursued CME activities. Twenty five per cent clearly declared that these activities do not satisfy CME needs and only 7\% thought positively of them (Figure 4). 
Eleni D. POLITI, Kyriakos N. SOULIOTIS. Understanding the Weaknesses and the Threats of Continuous Medical Education in the 21st Century

PROBLEMS

OF EDUCATION

IN THE $21^{\text {st }}$ CENTURY

Volume 56, 2013

CME credits reflect competency

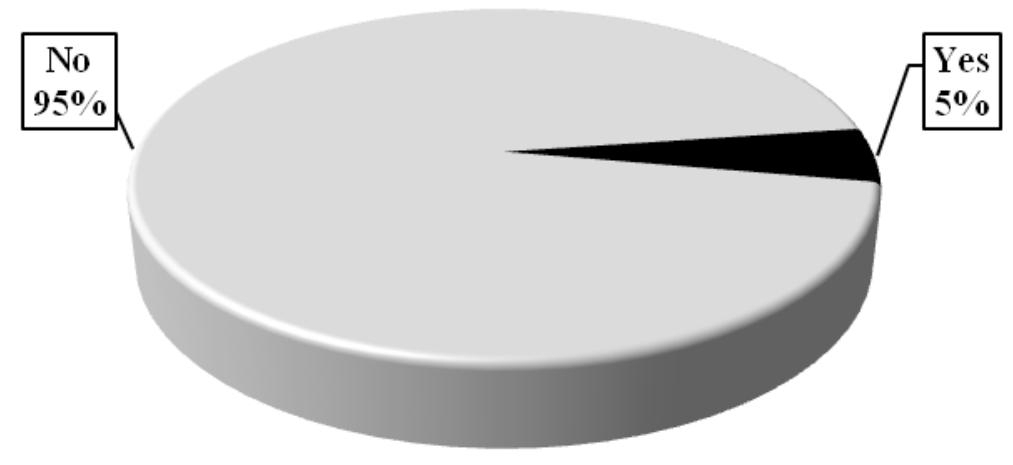

Figure 3: The corresponding doctors' opinion on the reflection of CME credits to medical competency.

Congresses attendance satisfy $\mathrm{CME}$ needs

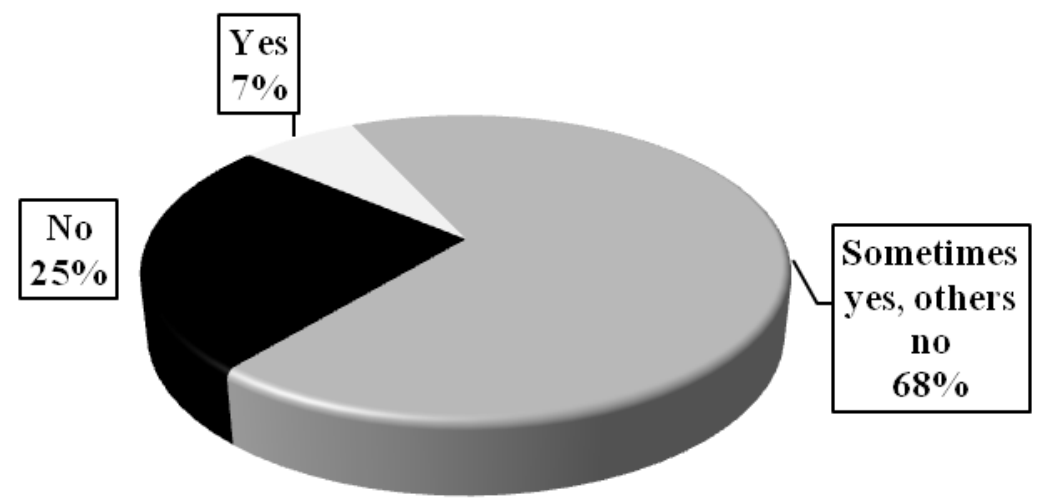

Figure 4: The corresponding doctors' opinion on CME needs satisfaction via congresses attendance.

Additionally, physicians of this sample were asked for their particular preferences regarding means of CME delivery. The majority of them appreciated combinations of different means i.e. both interpersonal methods, as well as e-learning. However, differences were identified among specialities. Network and information technology were more popular to the Internal medicine specialities, whereas interpersonal methods of training were more popular to the Surgical sector specialities. This probably explains the relatively low percentage of CME pursue that appeared for the Internal medicine specialities comparing to the other sectors, since online self-training is not yet officially considered as a pursue of an accreditated CME activity. 
Eleni D. POLITI, Kyriakos N. SOULIOTIS. Understanding the Weaknesses and the Threats of Continuous Medical Education in the 21st Century

\section{Access Difficulties}

Difficulties and discriminations in access were also underlined. Eighty one per cent of the corresponding physicians reported that it is not clear, neither easily feasible for them to find where to address their interest to receive specific CME and what relevant training opportunities may exist. However, older and specialized physicians, as well as the ones that studied Medicine in Greece appeared to be more knowledgeable on how to overcome such access difficulties. Still, though, the vast majority of the sample (92\%) highlighted the presence of geographic and financial discrimination in CME access (Figure 5). Fifty nine per cent revealed that CME needs are eventually satisfied via personal funding and $25 \%$ confessed that they do not manage to eventually satisfy their CME interests because of substantial access difficulties.

\section{Achieving CME is subject to geographic and/or financial limitations}

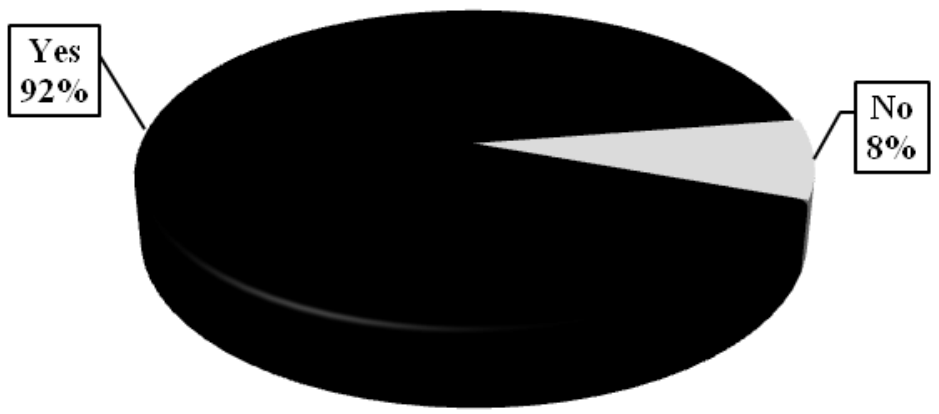

\section{Figure 5: The corresponding doctors' opinion on CME access difficulties.}

Despite the above though, there was a relatively high percentage (16\%) that declared they would never postpone CME due to access difficulties. This is an encouraging finding. It probably proves that the corresponding sample was strongly motivated to satisfy CME needs, although confessed difficulties. Considering the fact that the majority of the sample consists of young doctors, the satisfaction of CME needs against access difficulties and in particular financial ones should be even more recognized. It appears therefore that selected credits when attending CME activities may not be able to guarantee competency, but at least may prove a physician's ethical anxiety to keep updated in medical knowledge.

Finally, the majority of the corresponding physicians $(70 \%)$ considered the number of hours that should be obligatorily spent to CME should be at least 30 annually.

\section{Opinion on Establishing an Independent CME Authority}

The corresponding doctors were also asked on their opinion regarding the establishment of a National CME Center, that would be responsible for a central management of CME, providing relevant guidance and information to doctors, monitoring mandatory education and funding, coordinating and assessing provided CME activities in the nation. The majority of the sample considered the establishment of such a Center as very useful and indispensable, whereas a minority of $2 \%$ ranked it as indifferent. It is noteworthy that although statistical differences were not observed, the surgical specialities again seemed to validate the establishment of such a Center as "very important" to a higher extent compared to the other two sectors of medical specialities. 


\section{PROBLEMS \\ OF EDUCATION \\ IN THE $21^{\text {st }}$ CENTURY \\ Volume 56, 2013 \\ 112 Discussion}

Keeping up to date with the rapidly expanding medical knowledge is a challenging goal. Already from the ancient times of Hippocrates, doctors promised to keep up-to-date their knowledge and skills. Apart from knowledge, it is also skills, attitudes and values that consist what is overall called Continuous Professional Development (CPD), incorporating CME and going beyond it (Pissiotis \& Margiou, 2002).

Continuous Professional Development is defined as the educative means of updating, developing and enhancing how doctors apply knowledge, skills and attitudes required in their working lives (European Union of Medical Specialists, 2001). There are two ground rules though : physicians have themselves the responsibility to keep updated in knowledge and the responsibility to direct their own life-long learning (Toghill, 1998).

It seems that there is an anxiety nowadays to clarify what makes CME/CPD strategies successful in meeting their goals, meaning in serving the interests of patients and the public. To the authors' comprehension, successful CME/CPD strategies should principally address a variety of concepts that are below highlighted.

First, it is crucial that a physician not only appreciates the values of CME in general, but is clearly knowledgeable of the criteria he/she should use in order to specifically define and plan what exact CME priorities he/she has. One may desire to attend a variety of CME/ $\mathrm{CPD}$ activities. However, the driver to CME/CPD should be a focused goal to improve medical performance and outcomes in a particular field. Maybe patients' electronic files or electronic prescription platforms could be used as a mean to indirectly identify targeted CME/CPD needs via periodically reviewing the profile and the needs of the patients treated.

Second, there should be some rational on the available CME organizations and the scheduled activities. Plurality of sources of offered education is a desired condition. However, one should avoid polyphony and duplication of lectures, that might confuse CME prioritization and planning. Such overlaps may also waste resources against the investment of training to other thematic areas of professional development or to other CME means of delivery, such as telemedicine and e-learning. Successful personal CME planning implies accurate and in due time information on the available training opportunities and on their scope. It might be useful, therefore, to annually map via a centralized function the intended CME activities and ensure a satisfactory thematic, geographic and means of delivery distribution, before kicking off their approval to roll out.

Third, there should be strict quality assurance processes for the CME activities held. EACCME accreditation, commercial bias control, trainers' competency control and audiences' relevance and approval for participation must be all strictly audited actions. It is crucial that $\mathrm{CME} / \mathrm{CPD}$ values are protected, for physicians' trust, as well as for the public's interests.

Forth, it is essential that CME organizers satisfy the evolving needs of the audiences, encouraging their criticism and accordingly improve. The concept of audiences' assessment and feedback is supported and the CME organizers should be obliged to address in their proceeding activities the comments made.

Fifth, it is clear that is not only the selection of CME credits that ensures medical competency. Although a voluntary attendance to a training activity profiles a will to learn, however a direct link to competency cannot be guaranteed and it is far to be dependent on only hours of physical presence. Physicians' competency should be periodically, directly and indirectly officially measured and improved by additional means i.e. evaluation by supervisors and by patients, public health indexes in the area of practice, in-house traineeships to advanced centers or hands-on fellowships, self-assessment quiz tests etc.

Sixth, financial discrimination in education is an unpleasant fact. The governmental funding of CME activities and the direct and indirect taxation motives for physicians to be able to pursue life-long learning appear indispensable.

Last, but not least it seems that CME/CPD should be mandatory. Each practicing physi- 
cian should have a clearly predefined Personal Development Plan (PDP ) and should annually commit to meet its goals. However, the idea to threat physicians with relicensing penalties in

PROBLEMS

OF EDUCATION

IN THE $211^{\text {st }}$ CENTURY

Volume 56, 2013 case of failure is not supported, at least at this point. It is preferred to suggest that meeting the PDP requirements falls under general professional obligations, for which supervisors are also accountable. There should be therefore other kind of professional penalties that could control compliance, rather than sanction of license.

The most challenging element to address in CME is to evidently prove that the training interventions we use are directly related to better outcomes for the patients and for the public and this is probably the intrinsic weakness of the CME philosophy.

\section{Conclusions}

The ultimate goals in Medicine are to achieve high quality of care and better outcomes for the patients. In order to meet such goals, a continuous life-long training on new discoveries and technologies in medical sciences is demanded. However, translating the continuous medical education to real values for patients is a challenging process. It not only implies repeated educational interventions of high quality, but also a control on the relevance of the audiences and of the trainers, an ability and commitment to translate new knowledge to practical values and a structured plan for continuous professional development in general.

From the surveyed sample of physicians in Athens, a strong will and an appreciation for life-long medical education appeared. However, discriminations and access difficulties seemed to diminish the intended compliance. Doubt and skepticism for the effectiveness and the quality of the Greek CME/CPD system arose. Still though, Greek physicians seemed willing to even self-fund for CME, although the severe financial limitations of today. It has been encouraging having met practicing physicians that offered with enthusiasm to answer the study questionnaire and support this research, appearing to have agony for improvements in the national CME/CPD system.

It is a general concern how CME will manage to clearly meet its goals. Funding limitations on one hand and prioritization on pursued knowledge update on the other hand are important elements in the efforts to achieve successful personal CME plans. Progresses in medical sciences are extremely fast. Excuses though for delayed catch up are not accepted. The comprehensive, therefore, structure of an effective life-long educational system for adults that practice medicine is crucial.

Reforming a National CME/CPD system needs careful, stepwise and time consuming management. Any weaknesses it may carry may negatively reflect to a whole generation of practicing doctors. On that scope, the establishment of an independent, dedicated authority to systematically undertake this responsibility in Greece is proposed as an unmet need.

\section{Acknowledgements}

Data analysis has been performed with the valuable contribution of Ms Anastasia S Politi, PhD candidate from the Athens University of Economics and Business.

\section{References}

American Medical Association (2013), Continuing Medical Education for Licensure Reregistration (State Medical Licensure Requirements and Statistics). Retrieved 14/11/13 from: http://www. ama-assn.org/ama/pub/education-careers/becoming-physician/medical-licensure.page

European Union of Medical Specialists (2001), Basel Declaration, UEMS Policy on Continuing Professional Development. Retrieved 14/11/13 from http://www.uems.net/index.php?id=32

Fox, R. D., \& Bennett, N. L. (1998). Learning and change: implications for continuing medical education. British Medical Journal, 316, 466-8. doi: http://dx.doi.org/10.1136/bmj.316.7129.466. 
Eleni D. POLITI, Kyriakos N. SOULIOTIS. Understanding the Weaknesses and the Threats of Continuous Medical Education in the 21st Century

PROBLEMS

OF EDUCATION

IN THE $21^{\text {st }}$ CENTURY Volume 56, 2013

114 General Medical Council, Intelligence Unit Research (2011). Continous Professional Development The International Perspective, United Kingdom : Author George B. Murgatroyd Greek Ministry of Health \& Welfare (2012). Annual Report.

Institute of Medicine (2001). Crossing the Quality Chasm: A New Health System for the 21st Century. (Shaping the Future for Health) Washington, Authors: Brier R, Corrigan JM, Donaldson MS \& Kohn LT.

Levinson, W., (2008). Revalidation of physicians in Canada: Are we passing the test? Canadian Medical Association Journal Editorials, 179 (10), 979-980, doi:10.1503/cmaj.081342.

Lindsay, C., Morrison, J., \& Kelley, J. (1974). Professional ObsolescenceImplications for Continuing Professional Education, Adult Education Quarterly 25 (1), 3-22. doi: 10.1177/074171367402500101

Mc Partland, A. P., Ed.D (n.d.) Mandatory continuing education: Does it really protect society from incompetent health professionals ? Legal, Ethical, and Professional Issues in Psychoanalysis and Psychotherapy. Academy for the Study of the Psychoanalytic Arts. Retrieved 21/09/13 from http://www.academyprojects.org/mcpartland.htm.

NHS Formation (1983). Official Greek Government Gazette 1397.

Norman, G. R., Shannon, I. S., Marrin, L. M. (2004). The need for needs assessment in continuing medical Education, British Medical Journal Learning in Practice, 328, 999-1001. doi: http://dx.doi. org/10.1136/bmj.328.7446.999

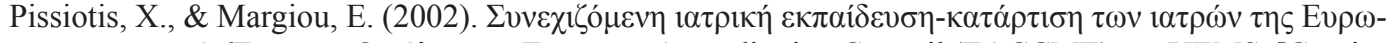

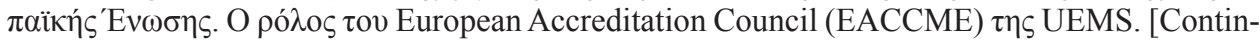
uous medical education-development of the medical doctors of the European Union. The role of the European Accreditation Council of UEMS]. Iatriko Vima: Hellenic Medical Association.

Sibley, J. C., Sackett, D. L., Neufeld, V., Gerrard, B., Rudnick, K. V., \& Fraser, W. (1982). A randomized trial of continuing medical education. New England Journal of Medicine 306 (9), 511-5. doi: 10.1056/NEJM198203043060904

The National Task Force on CME Provider/Industry Collaboration (n.d.). Fact Sheet, Retrieved 20/10/2013 from http://www.aafp.org/dam/AAFP/documents/cme/accreditation/cmea_NTF_facts 1.pdf

Toghill, P. (1998). Continuing medical education: where next? Doctors must manage their own education, British Medical Journal Editorials, 316 (7133), 721-722. Retrieved 20/10/2013 from http:// www.ncbi.nlm.nih.gov/pmc/articles/PMC1112722/

Advised by Laima Railiene, University of Siauliai, Lithuania

Received: September 21, 2013

Accepted: November 15, 2013

Eleni D. Politi

MD, PharmD, MPH, University of Peloponnese, Eratous Street, 18, Cholar-

gos, Athens, Greece.

E-mail: releni@yahoo.com

Kyriakos N. Souliotis

Assistant Professor of Health Policy, Faculty of Social Sciences

University of Peloponnese, Korinth, Greece.

Scientific Collaborator of the Centre for Health Services Research

Medical School, University of Athens, Greece.

Tel.: +30 2107482015 , Fax.: +30 2107485872.

E-mail: soulioti@hol.gr, ksouliotis@uop.gr 